\title{
O caminho se faz ao caminhar: atuações em Psicologia Escolar
}

\author{
Anabela Almeida Costa e Santos Peretta \\ Universidade Federal de Uberlândia - MG \\ Silvia Maria Cintra da Silva \\ Universidade Federal de Uberlândia - MG \\ Cláudia Silva de Souza \\ Docente da Escola de Educação Básica da Universidade Federal de Uberlândia - MG \\ Jaqueline Olina de Oliveira \\ Universidade Federal de Uberlândia - MG \\ Fabiana Marques Barbosa \\ Universidade Federal de Uberlândia - MG \\ Lílian Rodrigues de Sousa \\ Universidade Federal de Uberlândia - MG \\ Paula Cristina Medeiros Rezende \\ Universidade Federal de Uberlândia - MG
}

\begin{abstract}
Resumo
A Psicologia Escolar viveu um momento de crítica aos seus moldes tradicionais de atuação - baseados no diagnóstico e tratamento. Atualmente vem sendo priorizadas práticas comprometidas com a qualidade da educação. A presente pesquisa teve como objetivo conhecer práticas de psicólogos que atuam em secretarias de educação em 98 municípios de Minas Gerais. Por meio de questionários e entrevistas, foram buscadas informações sobre a história do serviço, a estrutura e as condições de trabalho, a atuação profissional e a fundamentação teórica adotada. Este artigo baseia-se em duas entrevistas e apresenta a prática de psicólogos que estão em consonância com a Psicologia Escolar Crítica. Considerase que importantes práticas vêm sendo desenvolvidas no sentido de que a Psicologia contribua para que a escola seja efetivamente espaço de humanização e apropriação do conhecimento, porém é relevante que haja políticas públicas que melhorem as condições de trabalho e ampliem as possibilidades de atuação do psicólogo nas instituições educacionais.
\end{abstract}

Palavras-chave: Atuação do psicólogo; Psicologia Escolar; políticas públicas

\section{The path is made by walking actions on School Psychology}

\begin{abstract}
School Psychology has experienced a moment of criticism on patterns of action from mainstream approaches based on diagnostic and treatment. Now, actions compromised with the quality of education have been prioritized. A research was done aiming at knowing psychologists' practices in municipal departments of education. This research has covered 98 cities from the Brazilian State of Minas Gerais. Questionnaires and interviews were used to search for information about the history of the service; structure and work conditions; professional practices; and theoretical backgrounds. This paper is based on two of those interviews, and presents practices from psychologists that are in consonance with the Critical School Psychology. We identify that important practices have been conducted in the sense that psychology contributes for the school, actually being a space for humanization and knowledge appropriation. However the study also reveals the importance of public policies that improve work conditions and extend possibilities of actions for the psychologist along education.
\end{abstract}

Keywords: psychologist practice; school psychology; public policies.

\section{El camino se hace al andar: actuaciones en Psicología Escolar}

\section{Resumen}

La Psicología Escolar vivió un momento de crítica en relación a moldes tradicionales de actuación con base en el diagnóstico y tratamiento. Actualmente, prácticas comprometidas con la calidad de la educación han sido priorizadas. Se realizó una investigación con la intención de conocer prácticas de psicólogos que actuan en secretarías de educación en 98 municipios de Minas Gerais. A través de cuestionarios y entrevistas se buscó informaciones sobre la historia del servicio, la estructura y condiciones de trabajo, la actuación profesional y la fundamentación teórica. Este artículo tiene por base dos entrevistas y presenta la práctica de psicólogos que están en conformidad com la Psicología Escolar Crítica. Se considera que se han desarrollado importantes prácticas en el sentido de que la psicología contribuya para que la escuela sea efectivamente espacio de humanización y apropiación del conocimiento, sin embargo se destaca la relevancia de que existan políticas públicas que mejoren las condiciones de trabajo y amplien las posibilidades de actuación del psicólogo en la educación.

Palabras Clave: actuação del psicólogo; psicología escolar; políticas públicas. 
O caminho se faz ao caminhar' ${ }^{1}$ : atuações em Psicologia Escolar

\section{Introdução}

Este artigo é fruto do estudo denominado "A atuação do psicólogo na rede pública de educação frente à demanda escolar: concepções, práticas e inovações"2, que buscou conhecer as atuações de psicólogos ligados às secretarias de educação dos estados de São Paulo, Minas Gerais, Paraná, Santa Catarina, Bahia, Rondônia e Acre. No Estado de Minas Gerais o estudo abrangeu 98 municípios e nos possibilitou conhecer um conjunto diverso de realidades vivenciadas e práticas desenvolvidas por profissionais da Psicologia. Apresentaremos no presente trabalho atuações de psicólogos de dois municípios mineiros. São modos de trabalho que denotam importantes aproximações com a Psicologia Escolar Crítica, caracterizada por se basear em intervenções institucionais que contemplam todos os envolvidos no processo de escolarização e por buscar práticas engajadas na defesa de uma educação de qualidade para todos. Trataremos de práticas desenvolvidas por psicólogos que diferem nas suas experiências e trajetórias, nas condições de trabalho, nos recursos de que dispõem e nas dimensões de seus municípios. Esses profissionais têm em comum a busca por construir práticas comprometidas com a melhoria das condições nos contextos escolares, visando ao pleno desenvolvimento dos sujeitos envolvidos no processo de escolarização. Assim, serão descritas práticas reais, repletas de conquistas, desafios e dificuldades e ações que sinalizam maneiras possíveis de atuação em Psicologia Escolar, área que viveu momentos de profunda transformação no que se refere ao modo de conceber suas práticas e concepções.

\subsection{Um breve percurso da Psicologia Escolar no Brasil}

Desde 1940 a Psicologia Escolar vem se constituindo como prática profissional no Brasil (Meira, 2000), mas foi a partir da década de 1960 que ela se fez mais presente nas escolas. Nessa época a atuação do psicólogo estava fundamentada em perspectivas psicológicas adaptacionistas e individualizantes, baseadas no modelo médico de atuação, o qual pressupunha o ajuste dos indivíduos ao meio em que viviam, descontextualizando-os de seus processos históricos de constituição. A partir de 1970 houve um crescimento da categoria do psicólogo escolar, embora este profissional

1 O título deste artigo inspirou-se no trecho "Caminante no hay camino, se hace camino al andar" do poema Proverbios y cantares, de Antonio Machado.

2 No âmbito nacional, a pesquisa foi coordenada pela Profa ${ }^{\text {. Dra }}$. Marilene Proença Rebello de Souza, da Universidade de São Paulo. Em Minas Gerais foi financiada pela FAPEMIG (Fundação de Apoio à Pesquisa de Minas Gerais - Edital Demanda Universal/APQ00014-08) e coordenada pela Profa ${ }^{\text {. Dra }}$. Silvia Maria Cintra da Silva, da Universidade Federal de Uberlândia. ainda estivesse pouco inserido no mercado de trabalho (Araújo, \& Almeida, 2005). Nessa mesma década iniciou-se um movimento de crítica e revisão dos fundamentos epistemológicos da Psicologia, a qual passou de uma ciência calcada na culpabilização do aluno pelo fracasso escolar para uma ciência que investiga as relações dialéticas entre indivíduo e sociedade, buscando interpretar a realidade como multideterminada (Tanamachi, 2000).

O percurso da Psicologia Escolar no Brasil foi revisado, sobretudo, a partir das contribuições de Maria Helena Souza Patto (1981, 1990), pioneira em questionar o lugar da Psicologia como ciência a serviço da ideologia dominante. Suas ideias colaboraram para incitar no psicólogo a compreensão das relações entre escola e sociedade no contexto da formação social capitalista e seus efeitos na prática escolar. Marilene Proença R. Souza (2000, 2007), Helenita R. Tanamachi (1992, 2003), Adriana M. Machado (2000, 2008), Marisa E. M. Meira (2000), Ana M. B. Bock (2000, 2007) são autoras que, baseadas em posicionamentos político-ideológicos e epistemológicos que têm como base o método materialista histórico-dialético, dedicaram-se à construção de uma perspectiva crítica em Psicologia Escolar, apontando modos diferenciados de se entender e agir sobre a realidade educacional (Souza, 2010). Neste sentido, resgatam o percurso histórico da Psicologia Escolar e questionam os modos de atuação profissional que ainda carregam o ranço da culpabilização de alunos, pais e professores pelo fracasso escolar e da medicalização dos problemas escolares.

\subsection{Psicologia Escolar: construindo novos rumos}

Conforme assinalado, a Psicologia Escolar Crítica viveu um necessário e importante movimento de crítica aos moldes de atuação tradicionais, momentos de profunda transformação em suas práticas e concepções; no entanto, como afirma Souza (2009):

O desafio agora principal da Psicologia Escolar é o de superação desse momento de crítica, considerando que já existem propostas interessantes e críticas de intervenção no campo da educação e estas propostas precisam se tornar mais visíveis entre os psicólogos e socialmente (p.181).

Buscar novos modos de fazer é instrumentalizarmo-nos para o desafio de desbravar a Educação e suas dificuldades atuais; é encontrar no arcabouço de conhecimentos da Psicologia recursos que contribuam para que os processos de ensino-aprendizagem sejam emancipatórios para todos os sujeitos nele envolvidos. É necessário adentrar e investigar a escola e pensá-la dentro de um contexto histórico-cultural e a partir das relações que nela são produzidas. Souza (2009) traz a importância de se compreender o fenômeno educacional como produto das relações que se estabelecem no interior da escola, lembrando que esta é atravessada por políticas educacionais e pela história local, por exemplo. Desconsiderar este contexto é analisar os efeitos e não as 
causas das queixas apresentadas e, deste modo, atuar com soluções paliativas e naturalizantes dos problemas, em que geralmente o aluno leva a culpa por não aprender.

É importante ressaltar que a escola é permeada por relações de poder, em cujos meandros são produzidos os processos de culpabilização do próprio aluno por seus problemas de aprendizagem. Ter consciência disto é essencial para quebrar esta lógica vigente, que se pauta por desigualdades, mas constitui-se como um grande desafio para todos os envolvidos. Muitas vezes o próprio psicólogo desconstrói a visão de "aluno-problema" para construir uma de "professor-problema", o que também não contribui para a transformação dessa realidade. Nesse sentido, Machado (2008) afirma:

Tem sido muito comum encontrar psicólogos que avaliam como absurdos os pedidos de atendimento individual feitos pelos professores e que se ressentem pelo fato de estes mesmos professores não quererem aquilo que os psicólogos propõem como forma de trabalho... Essa relação, que se opera quando julgamos negativamente a maneira do outro pensar, como se o pensamento dele fosse impedimento ao nosso trabalho, estabelece um vínculo de desigualdade, pois fica parecendo que a boa forma de agir é a de quem está tendo o poder de avaliar o outro (p. 5, grifo nosso).

Inaugurar modos de pensar e fazer tem colocado os psicólogos diante de diversos enfrentamentos e barreiras. Não é raro encontrarmos profissionais desanimados e resignados diante dos obstáculos. Ao longo de décadas, a Psicologia ensinou os profissionais da educação a encaminhar seus alunos a outros profissionais e a solicitar diagnósticos e tratamentos, construindo a concepção de que as crianças não aprendiam porque tinham problemas de ordem biológica, afetiva, cultural ou questões familiares. Machado (2008) afirma que esta é uma "crença" difícil de ser abalada, mas que as vias de ação da Psicologia Escolar não podem ser limitadas por ela. É essencial compreender por que os profissionais da Educação nos solicitam atendimentos. A partir disto, cria-se a possibilidade de transformar estes pedidos em propostas de intervenção mais amplas, que prevejam a participação dos diversos atores escolares. Machado (2008) aponta alguns direcionamentos sobre como transformar as demandas clássicas que chegam até o psicólogo em ações articuladoras das perspectivas dos sujeitos que perpassam o contexto escolar: é importante estar próximo dos professores, ouvi-los, discutir e problematizar os encaminhamentos, participar do dia a dia escolar e investigar hipóteses. Para tudo isso é necessário tempo para, junto com os professores, a direção, os pais e os alunos, pensar novas estratégias possíveis para o cotidiano escolar. Como destacam Tanamachi e Meira (2003, p. 53), "os possíveis beneficiários dos serviços de Psicologia devem ser, antes de mais nada, sujeitos ativos e não objetos passivos de ações sobre as quais não têm qualquer controle".

Diante da crescente discussão da Psicologia Escolar Crítica em torno de novos modos de conceber as contribui- ções do psicólogo para as relações que se dão no contexto escolar e das críticas cada vez mais presentes aos modelos tradicionais de atuação nesta área, faz-se necessário conhecer como têm se dado os esforços cotidianos para a construção efetiva da nova Psicologia Escolar. É importante compreender como as discussões têm ultrapassado o ambiente acadêmico e embasado concepções e práticas nas escolas e em outros espaços educativos. A pesquisa aqui apresentada foi realizada com o objetivo de identificar e analisar concepções e práticas desenvolvidas pelos psicólogos da rede pública quanto às queixas escolares oriundas do sistema educacional, visando compreender em que medida estas se aproximam das discussões recentes na área de Psicologia Escolar Crítica e apresentam elementos inovadores, em busca de um ensino de qualidade para todos. Neste artigo temos como objetivo apresentar atuações identificadas como bem-sucedidas no campo da Psicologia Escolar Crítica.

\section{Método}

Para conhecer como têm atuado os psicólogos da rede pública de educação, contatamos 98 municípios (11,49\% do total mineiro) e localizamos 123 psicólogos que atuavam em 41 destes municípios. A estes psicólogos enviamos questionários para recolher informações preliminares a respeito de seu trabalho na área da Educação. Os itens dos questionários abordavam as seguintes informações: a) dados pessoais; b) vínculo com a Secretaria de Educação, c) formação; d) atuação profissional; e) fundamentação teórico-metodológica. Obtivemos resposta de 32 profissionais (26,01\% do total encontrado).

Para identificar se as práticas relatadas nos questionários indicavam atuações em Psicologia Escolar e Educacional numa direção crítica, utilizou-se como base o procedimento adotado por Tanamachi em sua tese de doutorado, intitulada Visão Crítica de Educação e de Psicologia: elementos para a construção de uma visão crítica de Psicologia Escolar (1997). Para analisar as respostas dadas aos questionários foram observados os seguintes indícios de atuação crítica: 1- consideração das múltiplas determinações (sociais, econômicas, políticas, históricas) e da presença de concepção sobre o homem e sobre a educação; 2- contribuição teórico-prática articulada à realidade em que se está inserido; 3- pressupostos teórico-metodológicos/referência a autores do pensamento crítico e o modo como são apropriados; 4- explicitação de um compromisso técnico-político e/ou teórico-prático com a transformação da Psicologia.

Considerou-se que todos os elementos constitutivos de uma atuação crítica, apontados acima não seriam claramente observados em todos os itens de um mesmo questionário, assim buscou-se por indícios de criticidade. Além disso, classificar determinada atuação como "crítica" ou "não crítica" significaria operar de acordo com a lógica formal, ou seja, sem considerar a multideterminação dos fenômenos, o que é compreendido como essencial a partir do referencial teórico adotado. Com a leitura das respostas, observou-se 
que muitas delas apresentavam tanto elementos críticos quanto não críticos, encontrando-se numa linha contínua entre estes dois polos. Dessa forma, a presença de qualquer um dos elementos constitutivos de uma atuação crítica, inovadora, ou não crítica, tradicional, não necessariamente resultaria em uma classificação direta da atuação do psicólogo participante como crítica ou não crítica, respectivamente. Por isso, na seleção para a segunda etapa da pesquisa foi realizada a análise de cada questionário como um todo, buscando-se identificar quais participantes apresentavam mais tendências à criticidade em sua atuação e verificando a coerência interna entre as respostas dadas.

Foram considerados elementos críticos aqueles caracterizados por uma atuação que contemplasse as multideterminações dos fenômenos educacionais e buscasse incluir os diversos atores escolares na superação das queixas. Consideramos elementos não críticos aqueles marcados por uma atuação que centrasse a queixa escolar no indivíduo (geralmente no aluno e em sua família), desconsiderando as relações institucionais e a multiplicidade de determinações sociais e históricas que a produzem.

Selecionamos 14 psicólogos para participarem da segunda etapa da pesquisa, a das entrevistas, a fim de aprofundar o conhecimento sobre a atuação dos psicólogos. Foram, então, realizadas entrevistas com seis psicólogos e quatro equipes, de oito municípios mineiros. As entrevistas foram analisadas visando conhecer: a) o serviço em que atuam; b) atuação desenvolvida; c) fundamentação teórica que embasava a atuação.

As entrevistas foram analisadas com base nos mesmos critérios utilizados para os questionários. A partir da análise dos serviços com os quais entramos em contato, constatamos que dois municípios contemplaram de forma mais completa e significativa os requisitos: presença de indícios de uma atuação com perspectiva inovadora e coerente com as proposições da área de Psicologia Escolar Crítica. A seguir, serão apresentados os resultados da análise das informações referentes à atuação desses psicólogos.

\section{Resultados}

Apresentaremos a atuação de psicólogos em dois contextos de trabalho diversos. O primeiro serviço - que denominaremos MG1 - é mais antigo, tendo surgido em meados da década de 1980. O segundo - MG2 - era bastante recente quando foi realizado o estudo: foi iniciado em 2008, a partir do primeiro concurso feito na cidade para a área de Psicologia, ocorrido em 2007. Também são diferentes as dimensões e as condições dos municípios em que se encontram. MG1 localiza-se em um município com cerca de 80 mil habitantes, marcadamente urbano, que tem nos setores de comércio e serviços sua sustentação econômica basilar. A rede de educação do município atende mais de oito mil alunos. Já MG2 encontra-se em um município de menores dimensões, que tem pouco mais de 10 mil habitantes. É uma cidade predominantemente rural, que tem na agricultura $\mathrm{e}$ na pecuária suas principais fontes de renda. A rede de educação da cidade atende cerca de três mil alunos.

Em MG1 existia uma equipe de profissionais (incluindo psicólogos, concursados desde bastante tempo, assistentes sociais, terapeutas ocupacionais, psicopedagogos e fonoaudiólogos) que buscava uma visão multidisciplinar ou transdisciplinar. Já em MG2, o entrevistado atuava sozinho, pois era o único psicólogo escolar, não contando com uma equipe para conduzir o trabalho junto às escolas.

A despeito de tantas diferenças, alguns aspectos são comuns aos dois municípios em questão. A jornada de trabalho em ambos é de 20 horas semanais, o que é sentido pelos profissionais como insuficiente para atender às demandas da educação municipal. Também é recorrente o fato de os profissionais complementarem a renda com outros empregos. Em nenhum dos serviços há plano de carreira para o psicólogo. Em MG1, os profissionais relatam que o plano de cargos e salários já foi aprovado, mas o de carreira, por questões políticas, ainda não. Aqueles psicólogos que estão trabalhando há mais tempo recebem um pouco mais, pois há uma política salarial que prevê adicionais por tempo de serviço. Em MG2 os profissionais recebem apenas o salário, sem benefícios.

\subsection{Os psicólogos mediante as demandas e os problemas nos processos de escolarização}

Tanto em MG1 quanto em MG2 encontramos psicólogos dispostos a construir e trilhar caminhos para atender às demandas das escolas e para enfrentar os mais diversos problemas que surgem no processo de escolarização. Seus trabalhos têm sido repletos de dificuldades, desafios e, sobretudo, conquistas construídas no dia a dia das escolas. Em ambos os municípios os psicólogos relataram receber pedidos bastante tradicionais das escolas: "as queixas maiores que chegam para mim lá é de comportamento, dificuldade de aprendizagem" (MG2). Em MG1, uma psicóloga repetiu a fala recorrente dos professores de seu município direcionada aos psicólogos: "ai, eu estou cheia de menino com problema, vamos lá pra vocês verem". Identifica-se nas demandas feitas pelas equipes das escolas uma concepção tradicional de Psicologia, baseada no atendimento clínico aos alunos e na compreensão das questões escolares como causadas por questões individuais.

Sabe-se que este tipo de pedido foi historicamente construído pela própria Psicologia (Patto, 1984, 1990; Bock, 2000; Souza, 2000); como, então, conduzir um trabalho que abranja todos os envolvidos e promova transformações no contexto em que as queixas estão sendo produzidas? Sem desconsiderar o que lhes é pedido, em ambos os municípios os profissionais destacam privilegiar o trabalho de intervenção institucional junto ao corpo docente, à coordenação pedagógica e à equipe gestora da escola. Criam estratégias para acolher as demandas e, simultaneamente, envolvem a comunidade escolar no enfrentamento do que a mobiliza. Enfrentam resistências e inventam e reinventam práticas na 
busca por construir um reconhecimento como psicólogos escolares.

Em MG2, onde o serviço de psicologia é recém-implantado e conta com um único profissional, ainda é empreendida uma busca por estabelecer uma identidade de trabalho junto às equipes das escolas, pois os professores esperam a atuação clínica. O psicólogo diz evitar atender alunos individualmente, afinal não tem identificado esta necessidade e, assim, opta por desenvolver suas ações ora com os professores ora com toda a sala de aula:

Eu faço um trabalho mais diversificado, eu não fico tanto só em atendimento... E os professores se queixam de que não há atendimento com os alunos. Eles acham que, mesmo eu indo lá na sala de aula, isso não é atendimento.... Pelo menos eu estou tentando mudar essa ideia deles do que é o trabalho do psicólogo na escola, né? (MG2)

O psicólogo traz uma visão ampliada do que seria atender às demandas, pois intervir junto a professores, a salas de aula, à direção e à coordenação escolar também é uma forma de atender à queixa escolar. Quando o atendimento clínico se revela necessário, há um investimento no sentido de que o professor se envolva na resolução da queixa. O psicólogo afirmou: "Eu não aceito a criança [para realizar o atendimento clínico] sem antes conversar com o professor" (MG 2). Assim ela faz visitas de orientação pelo menos uma vez por mês a cada escola ${ }_{1}$ inclusive às da zona rural:

Eu tenho ido, eu vou pelo menos uma vez por mês em cada escola, eu vou lá para a zona rural, vou junto com os professores. Levanto cinco horas da manhã, pego o ônibus, vou lá para a zona rural e vou às escolas.... E lá nas escolas eu converso principalmente com os professores para saber quais estão sendo as dificuldades. E lá eu já dou uma orientação para eles. (MG2)

Ele faz apontamentos, questionamentos e reflexões sobre como têm sido as práticas em sala de aula; problematiza os rótulos dados aos alunos; traz a necessidade da prática reflexiva e do trabalho em equipe em vez da ação desarticulada de professores e psicólogo.

O psicólogo contou que a realização dessas reuniões de orientação dependia da dinâmica da escola, do momento vivido pelos professores e das possibilidades de tempo destes. Algumas vezes, a única possibilidade existente eram os 15 minutos de intervalo. Assim, este era o tempo que utilizava para a reunião, que poderia ser com um único professor ou com grupos. Outras vezes conseguia realizar reuniões mais demoradas, organizar grupos de estudo que ajudassem a refletir sobre temáticas eleitas pelos docentes. O psicólogo descreveu essas orientações como momentos de construir junto com o professor modos de trabalhar com os conteúdos pedagógicos, propor atividades e avaliar os alunos: "A gente procura juntos, eu e o professor, estratégias para ajudar aquela criança." (MG2). Percebe-se uma preocupação constante em estabelecer relações horizontais com os professores, instigando diálogos em que os saberes da Educação e da Psicologia se encontrem na busca por produzir mudanças e por construir relações de ensino-aprendizagem que promovam o desenvolvimento e a participação efetiva dos alunos. A avaliação, por exemplo, foi um tema abordado nos encontros com os professores em que o psicólogo interveio no sentido de questionar o caráter apenas quantitativo deste processo, ressaltando que a avaliação pode ser também um momento de aprendizagem.

Em MG1, também foi possível conhecer importantes estratégias desenvolvidas pelos profissionais a fim de garantir uma ação comprometida com a qualidade da educação pública. Neste caso, uma equipe numerosa, experiente e com uma trajetória atravessada por inconstâncias políticas desenvolveu um trabalho consolidado e bem-definido.

"O que a Psicologia faz na escola?"; "Qual é o trabalho que desenvolve junto à educação?". Estas são perguntas recorrentes que são feitas aos/pelos psicólogos escolares. Tais questões remetem à história da Psicologia Escolar, uma área de conhecimento que enfrentou mudanças no modo de conceber seu objeto e suas práticas. Como afirma Costa (2007, p. 7), "quando se trocam as lentes através das quais se olha para o mundo e para as coisas, quase tudo é novo e uma imensa tarefa se descortina diante de nós". Reconstruir as práticas e, além disso, as expectativas daqueles com quem se trabalha é um importante desafio. Em MG1, a equipe encontrou caminhos para constituir uma identidade de seu trabalho e responder às dúvidas das escolas sobre o que podiam oferecer: desenvolveu e sistematizou um projeto de trabalho com ações claramente definidas e nomeadas ${ }^{3}$, apresentadas em reuniões periódicas com as equipes das escolas:

Então, a gente pede que elas [as escolas] mandem pra gente um pedido de atuação já bem delineado. Quando não está delineado, a gente faz uma conversa pra montar um contrato com a escola.... Isso facilita muito na hora da gente atuar e pra eles também, eu acho, pra entender o que vai ser o papel da gente lá, né?(MG1)

Há um investimento grande na negociação que antecede o início efetivo do trabalho. Nesse sentido, são realizados ajustes das expectativas e uma afinação entre o que é pedido e o que a equipe da Psicologia efetivamente pode oferecer, num trabalho que visa esclarecer e construir junto à escola o que a Psicologia Escolar pode fazer. Este processo também é sistematizado e nomeado, consistindo em procedimentos como a "retificação da queixa" e o "diagnóstico situacional", ações utilizadas quando o pedido da escola é feito no formato de encaminhamentos de alunos para atendimento clínico. Neste caso, a equipe da escola é convidada a discutir a intervenção mais adequada, ou seja, promove-se uma reflexão a respeito do que está sendo pedido, para avaliarem se existem outros fatores que não os individuais atuando na produção daquela queixa. Trata-se da "retificação da queixa", que tem o objetivo de mudar o foco da atenção, ou seja, em

3 Para preservar a identidade dos psicólogos e do município, não serão citados todos os nomes dos projetos desenvolvidos. 
vez de se buscar uma suposta patologia da criança, abre-se a possibilidade para que seja realizado, então, o "diagnóstico situacional". Este_procedimento consiste em o psicólogo escolar construir, com a equipe da escola, um diagnóstico que considere a situação na qual a criança está envolvida; ou seja, desvia-se o foco do diagnóstico da criança para o contexto no qual ela está inserida. Assim, os participantes consideram que a determinação da queixa "pode ser tanto do âmbito das relações, quanto do âmbito institucional, quanto do âmbito, vamos dizer, social mesmo, em que bairro essa escola está e quais são as circunstâncias desse bairro, como é que isso influi, né?" (MG1).

Ambos os serviços demonstram preocupação em definir o papel do psicólogo escolar em seus serviços, procurando consolidar ações profissionais mais adequadas às demandas do sistema educacional, que sejam específicas da Psicologia Escolar e que convirjam com o referencial crítico, por meio de práticas abrangentes e contextualizadas, indicando uma ruptura com os moldes tradicionais.

\subsection{O psicólogo escolar diante dos rótulos e preconceitos produzidos no contexto escolar}

Um dos desafios da perspectiva crítica em Psicologia Escolar é impedir que os problemas que ocorrem no processo de escolarização sejam confundidos ou tratados como "problemas de aprendizagem do aluno" e cristalizados em rótulos como "aluno desinteressado", "aluno problemático", gerando preconceitos e interferindo negativamente na prática pedagógica. Diante disso, os posicionamentos da Psicologia Escolar Crítica direcionam-se no sentido de compreender o fracasso escolar como uma construção coletiva e que demanda, como tal, a busca de estratégias coletivas e relacionais para ser resolvido.

Nesse sentido, em MG1 destacamos um trabalho realizado pela equipe multidisciplinar - composta por psicólogos, fonoaudiólogos, psicopedagogos e terapeuta ocupacional - que se dedica a fazer um trabalho de "investigação dos problemas de aprendizagem", para a discussão dos casos/queixas e seus encaminhamentos necessários. O grupo propõe um "diagnóstico diferencial" de casos que chegam rotulados como dislexia e Transtorno do Déficit de Atenção e Hiperatividade (TDAH), contestando a naturalização e padronização de rótulos de doenças relacionadas ao fracasso escolar. Importa ressaltar que o grupo tem um cuidado especial em não medicalizar os problemas escolares, por isso está bem atento para "não deixar que decisões que são do campo educacional, do ponto de vista da própria disciplina da escola, da própria vida da escola sejam colocadas na criança como algo a ser tratável" (MG1).

Observamos que os profissionais entrevistados destinam a maior parte de sua carga horária ao trabalho institucional, realizando atividades com os professores, buscando implicá-los nas reflexões e decisões inerentes ao processo ensino-aprendizagem, retirando o foco da culpabilização única pelo fracasso escolar - seja esta do aluno ou do docente.
Em MG2, merece destaque a realização de grupos de estudos com os professores acerca da temática da inclusão e da acessibilidade. O psicólogo diz que "os resultados vêm em longo prazo; para que se tire o rótulo do louco ou deficiente são necessárias mudanças profundas de pensamento" (MG2). Além disso, ele orienta professores que receberão alunos com deficiências em sua sala, buscando diminuir a sua ansiedade em relação ao fato e possibilitando o contato dos docentes com profissionais das instituições de educação especial que acompanharam as crianças antes de estas irem para o ensino regular. Com isso, o psicólogo colabora para desconstruir rótulos e desmistificar ideias preconceituosas acerca do estudante com deficiência ${ }^{4}$.

Outra ação a ser destacada em MG2 é a realização de pesquisas em parceria com o corpo docente das escolas. O profissional narrou uma investigação desenvolvida com a colaboração de professores das escolas por ele assessoradas, ressaltando que o tema da pesquisa surgira das queixas dos professores que se centravam nos alunos: "o aluno não tem interesse, os alunos não querem saber de nada, famílias desestruturadas" (MG2). Diante das alegações de que os alunos tinham perdido o interesse pela escola e, por esta razão, não se envolviam nas atividades propostas em sala de aula, o psicólogo convidou o grupo de docentes para que, juntos, realizassem uma pesquisa com 150 alunos, buscando identificar a concepção destes sobre o estudo e a escola. Os professores participaram de todas as etapas: elaboração de questionário, aplicação e análise dos resultados. O resultado do estudo apontou que os alunos "têm interesse, querem estudar, só que eles pedem mudanças nas atividades, pedem mudanças nas atividades em sala de aula; foi uma grande maioria dos alunos que colocaram que gostaria que tivesse mudança" (MG2).

Diante destes resultados, o psicólogo questionou o modelo pedagógico que tem sido reproduzido na escola, onde predomina a cena: "aluno sentado na cadeira e professor lá na frente, aquela aula só expositiva” (MG2). De acordo com o profissional, estando-se de posse dos resultados da investigação e procedendo-se à sua divulgação, os professores sentiram-se surpreendidos, porque, contradizendo as suas concepções sobre o que os alunos sentem em relação ao espaço escolar, as informações indicaram que os alunos gostam da escola, embora se queixassem de questões pedagógicas como a dinâmica das aulas e a didática dos professores.

Desse modo, a pesquisa provocou mudanças na concepção dos docentes sobre os seus alunos, com efeitos na própria prática pedagógica, indicando que o desenvolvimento de pesquisas no interior da escola constitui-se como alternativa possível para que, por meio delas, o psicólogo possa desenvolver um trabalho crítico partindo de dados concretos e assim favorecendo a superação dos rótulos e preconceitos produzidos no contexto escolar.

4 Mais informações a respeito da atuação na Educação Inclusiva dos psicólogos da rede pública de educação do Estado de Minas Gerais podem ser encontradas em Santos e cols., (2011). 


\subsection{O psicólogo diante dos obstáculos político- institucionais}

Os profissionais relataram dificuldades diversas em realizar suas práticas. Em MG1, o principal obstáculo são as relações políticas com a Secretaria de Educação do município e a instabilidade gerada a cada nova gestão eleita. Nessa localidade a equipe tem uma longa trajetória de trabaIho e passou por diversas mudanças no cenário político. Por exemplo, no início do serviço, durante alguns anos houve um psicólogo em cada escola da rede pública, mas em uma das mudanças de prefeito o trabalho de Psicologia Escolar foi extinto. Deste modo, o Serviço de Psicologia do município ficou por dezesseis anos limitado a atuar apenas com atendimentos clínicos, não contemplando nenhum trabalho de Psicologia Escolar e Educacional.

Esta situação foi revertida quando a psicóloga entrevistada, a mais antiga do serviço, assumiu a direção do centro de Psicologia. Valendo-se de uma conjuntura política favorável, ela elaborou um plano de trabalho que incluía a volta da Psicologia Escolar e Educacional. O projeto foi adotado, mas não foi alcançado em sua amplitude, algo evidenciado na fala de um membro da equipe: "A estrutura ainda é precária e a gente corre atrás realmente para atender dentro das melhores maneiras possíveis às demandas que chegam pra gente hoje" (MG1).

A psicóloga demonstrou, por meio de uma ação propositiva e articulada, que o melhor caminho não seria a estagnação perante o histórico de atendimento clínico que o centro possuía, mas sim, o aproveitamento das possibilidades e das oportunidades que surgem quando estamos atentos e disponíveis para elas.

Neste sentido, Deleuze (1990), autor francês que tem inspirado transformações e inovações na Psicologia em suas diversas áreas de atuação, aponta que a criação do novo é um processo de subjetivação coletiva e individual, e afirma:

Tais processos têm valor na medida em que, ao ocorrerem, escapam tanto dos saberes constituídos quanto dos poderes dominantes. Mesmo se eventualmente engendram novos poderes, evocam novos saberes. Em seu surgimento, todavia, eles têm uma espontaneidade rebelde.... Eles vêm à tona por um instante, e é este momento que é importante, é a oportunidade que deve ser agarrada. (p. 72)

A busca por novas vias de ser e de se constituir mostra-se o grande criador de possibilidades e devires. Para Deleuze (1990, p. 68), "o devir não é história, a história marca somente o conjunto de condições - por mais recentes que sejam - das quais desviamos para 'devirmos', quer dizer, para criarmos alguma coisa de novo."

A trajetória de MG1 revela vontade de criar e de romper com o instituído, movimentos que culminaram na criação do Centro de Psicologia da cidade, que trabalha envolvendo as escolas do município diretamente em suas ações.

Outra dificuldade enfrentada pela equipe de MG1 é a relação com algumas diretoras de escola, as quais se colo- cam contrárias aos serviços propostos, que visam a uma relação de trabalho com a escola, e não só com os estudantes. Por vezes essas diretoras levaram reclamações à Secretaria de Educação do município e os psicólogos foram ameaçados de perder o emprego. Para enfrentar esta questão, os profissionais buscam atuar em instituições que se mostrem mais abertas às suas propostas.

Em MG2, o psicólogo também precisa transpor barreiras de estagnação e propor o novo para consolidar práticas diferenciadas e eficientes em seu trabalho com os professores das escolas. A relação com eles têm sido difícil principalmente porque o estereótipo do psicólogo clínico orienta-se pela concepção vigente, de modo que alguns professores se mostram indispostos ao trabalho de caráter psicoeducacional feito pelo profissional. Além disso, por ser o único psicólogo contratado pela prefeitura, ele afirma exercer um trabalho solitário, que conta com precária estrutura de apoio institucional, não tem recursos para participar de congressos e cursos de supervisão nem materiais para o desenvolvimento do trabalho.

Como estratégia de atuação, ele busca desmistificar expectativas idealizadas no dia a dia, com conversas que estimulem a autocrítica e reflexão dos professores, sempre com muita tranquilidade e respeito, mostrando-Ihes que diante deles não há nenhum superior, mas sim, um colega de trabalho que deseja mudanças e propõe novos modos de conceber e agir na escola. Tal postura foi importante para a realização da pesquisa que desenvolveu junto com os professores, pois abriu espaço para novos olhares nestes contextos escolares.

Ademais, foi apontada nas entrevistas a necessidade de formação continuada, algo buscado e realizado dentro das possibilidades dos profissionais, incluindo desde leituras e conversas até congressos e espaços de formação teórica. Por meio destas buscas são gerados novos espaços de reflexão e trocas, como um ar novo para retornar à escola, levando também aos professores essas perspectivas, fundamentais perante as dificuldades do cotidiano.

\section{Considerações finais}

Este artigo teve o objetivo de apresentar a prática de psicólogos da rede pública de educação que trabalham em dois municípios mineiros. Pretendíamos discutir elementos que indicassem ser possível realizar um trabalho em Psicologia Escolar Critica capaz de superar as concepções e fazeres tradicionais de cunho clínico, medicalizante e individualizado, a despeito das dificuldades de ordem ideológica, política, social e estrutural enfrentadas pelos profissionais, embora esta empreitada exija esforço, investimento contínuo em formação, inserção política, uma boa dose de persistência e, quiçá, obstinação.

Nesse sentido, o psicólogo escolar, diante dos obstáculos político-institucionais, das demandas e problemas de escolarização, dos rótulos e preconceitos produzidos no contexto escolar, pode colocar as possibilidades acima 
das dificuldades e, sob este enfoque, as experiências bem-sucedidas precisam ser divulgadas e multiplicadas.

Ainda que bons trabalhos venham sendo desenvolvidos, vale destacar a premente necessidade de que as secretarias de Educação reconheçam e valorizem o trabalho do psicólogo escolar, condição fundamental para que tais ações possam ser fortalecidas. Destaca-se a relevância de realizar concursos específicos para a área da Educação e de implementar planos de carreira que valorizem a profissão e o apoio para que os profissionais possam investir em sua formação continuada.

Neste trabalho, foram apresentados dois modos de intervenção e articulação da Psicologia com os contextos escolares. Certamente, muitos são os psicólogos que em seu dia a dia constroem caminhos no sentido de contribuir para que a escola seja, efetivamente, um espaço de humanização e de apropriação de conhecimento. Assim, faz-se necessário que outros estudos sejam desenvolvidos a fim de trazer a público práticas emancipatórias em Psicologia Escolar.

Foi bastante gratificante encontrar, em meio a tantos percalços, psicólogos dispostos a construir, no seu dia a dia de trabalho, caminhos que buscam um trabalho comprometido com a qualidade da educação pública e com uma psicologia não excludente, rompendo com o instituído e oferecendo às instituições educacionais um trabalho baseado no envolvimento da comunidade escolar no enfrentamento das questões que surgem no processo de escolarização, promovendo a autonomia de alunos e profissionais de educação e trabalhando no sentido de desconstruir preconceitos vigentes no contexto escolar. Estas atuações são reais e possíveis em Psicologia Escolar e podem instigar importantes reflexões teórico-práticas. Encerramos com inspiradoras palavras de Deleuze (1990):

Acreditar no mundo é o mais que nos falta; perdemos o mundo; ele nos foi tomado. Acreditar no mundo é também suscitar acontecimentos, mesmo que pequenos, que escapem do controle, ou então fazer nascer novos espaçostempos, mesmo de superfície e volume reduzidos.... É ao nível de cada tentativa que são julgadas a capacidade de resistência ou, ao contrário, a submissão a um controle (p. 73).

\section{Referências}

Araújo, C. M.A., \& Almeida, S. F. C. (2005). Psicologia Escolar: construção e consolidação da identidade profissional. Campinas, SP: Alínea.

Bock, A. M. B. (2000). As influências do Barão de Münchhausen na Psicologia da Educação. Em E. Tanamachi, M. Proença \& M. Rocha (Orgs.).Psicologia e educação: desafios teórico-práticos (pp.11-33). São Paulo: Casa do Psicólogo.

Bock, A. M. B. (2007). A Psicologia sócio-histórica: uma perspectiva crítica em psicologia. Em A. M. B. Bock, M. G. M Gonçalves, \& O.
Furtado (Orgs.).Psicologia sócio-histórica: uma perspectiva crítica em psicologia (pp. 15-35). São Paulo: Cortez.

Costa, M. V. (2007). Prefácio. Em A. Marcondes, A. Fernandes, \&M. Rocha (Orgs), Novos possíveis no encontro da psicologia com a educação, (pp. 7-9). São Paulo: Casa do Psicólogo.

Deleuze, G. (1990). O devir revolucionário e as criações políticas (entrevista a Toni Negri). Revista Novos estudos CEBRAP, 28. Recuperado: 21 out. 2011. Disponível: http://pt.scribd.com/ doc/59831719/O-Devir-Revolucionario-e-as-Criacoes- PoliticasGILLES-DELEUZE-A-TONI-NEGRI.

Machado, A. M. (2000). Avaliação psicológica na educação: mudanças Necessárias. Em: M. Rocha, E. Tanamachi, \& M. Proença (Orgs.). Psicologia Escolar: Desafios teórico-práticos (pp.143-168). São Paulo: Casa do Psicólogo.

Machado, A. M. (2008). A produção das desigualdades nas práticas de orientação (trabalho apresentado no CEU Butantã, no âmbito do Projeto Direitos Humanos nas escolas). Recuperado: 27 ago. 2012. Disponível: http://www2.fe.usp.br/ cpedh/Desigualdade $\% 20$ e\%20Educ\%20Adriana\%20Marc.pdf

Meira, M. E. M. (2000). Psicologia Escolar: Pensamento Crítico e Práticas Profissionais. Em: E. R. Tanamachi; M. L. Rocha; \& M. Proença (Orgs.). Psicologia e Educação: desafios teórico-práticos (pp. 35-72). São Paulo: Casa do Psicólogo.

Patto, M. H. S. (Org). (1981). Introdução à Psicologia Escolar. São Paulo: T.A. Queiroz.

Patto, M. H. S. (1984). Psicologia e Ideologia: Uma introdução crítica à Psicologia Escolar. São Paulo: T.A. Queiroz.

Patto, M. H. S. (1990). A produção do fracasso escolar: Histórias de submissão e rebeldia. São Paulo: T.A. Queiróz.

Santos, A. A. C., Silva, S. M. C., Rezende, P. C, Souza, C. S., Souza, F. M., Oliveira, J. O. Sousa, L. R. (2011). Educação Inclusiva e o psicólogo da rede pública de educação de Minas Gerais. Em C. Dechichi, L. C. Silva, \& J. M. Ferreira (Orgs). Educação Especial e Inclusão Educacional: formação profissional e experiências em diferentes contextos (pp. 113-146). Uberlândia, MG: Edufu.

Souza, M. P. R. (2000). A queixa escolar na formação de psicólogos: desafios e perspectivas. Em E. R. Tanamachi, M. Proença \& M. Rocha (Orgs.). Psicologia e Educação: Desafios teórico-práticos (pp. 105-142). São Paulo: Casa do Psicólogo.

Souza, M. P. R. (2007). Prontuários revelando os bastidores do atendimento psicológico à queixa escolar (pp. 27-58). Em B. P. Souza (Org.). Orientação à queixa escolar. São Paulo: Casa do Psicólogo.

Souza, M.P.R. (2009). Psicologia Escolar e Educacional em busca de novas perspectivas. Revista Psicologia Escolar e Educacional, 
13(1), 179-182

Souza, C. S.(2010). A atuação do psicólogo escolar na rede particular de ensino da cidade de Uberlândia - MG. Dissertação de mestrado, Instituto de Psicologia, Universidade Federal de Uberlândia, Uberlândia- MG.

Tanamachi, E. R. (1992).Psicologia Escolar: Tendências e avanços da Psicologia na educação escolar. Dissertação de Mestrado, Instituto de Psicologia, Universidade Estadual de São Paulo, Marília-SP.

Tanamachi, E. R. (1997). Visão crítica de Educação e de Psicologia: elementos para a construção de uma visão crítica de Psicologia
Escolar. Tese de Doutorado, Universidade Estadual Paulista, Marília, São Paulo.

Tanamachi, E. R. (2000). Mediações teórico-práticas de uma visão crítica em Psicologia Escolar. Em E. R.Tanamachi, M. Proença \& M. Rocha (Orgs.).Psicologia e Educação: Desafios teóricopráticos_(pp. 73-104). São Paulo: Casa do Psicólogo.

Tanamachi, E.R., \& Meira, M.E.M. (2003). A atuação do psicólogo como expressão do pensamento crítico em Psicologia e Educação. Em M. E. M.Meira \& M. A.M. Antunes, (Orgs.).Psicologia Escolar: Práticas críticas (pp. 11-62). São Paulo: Casa do Psicólogo.

\section{Sobre as autoras}

Anabela Almeida Costa e Santos Peretta (anabelaacs@gmail.com)

Docente do Instituto de Psicologia da Universidade Federal de Uberlândia (UFU), Doutora em Psicologia Escolar e do Desenvolvimento Humano pela Universidade de São Paulo

Silvia Maria Cintra da Silva (silvia_ufu@hotmail.com)

Docente do Instituto de Psicologia da Universidade Federal de Uberlândia (UFU), Doutora em Educação

Cláudia Silva de Souza (psicastella@yahoo.com.br)

Docente da Escola de Educação Básica da Universidade Federal de Uberlândia (ESEBA/UFU), Doutoranda em Educação pela UFU

Jaqueline Olina de Oliveira (jaqueline_olina@hotmail.com)

Graduanda em Psicologia pela Universidade Federal de Uberlândia (UFU)

Fabiana Marques Barbosa (fabi.marques@hotmail.com)

Psicóloga, Mestranda em Psicologia pela Universidade Federal de Uberlândia (UFU).

Lílian Rodrigues de Sousa (lilian_patos@yahoo.com.br)

Psicóloga.

Paula Cristina Medeiros Rezende (lalamedeiros@netsite.com.br)

Docente do Instituto de Psicologia da Universidade Federal de Uberlândia (UFU), Doutora em Psicologia pela Universidade de São Paulo. 